\title{
Continued Benefit of Tocilizumab Plus Disease-modifying Antirheumatic Drug Therapy in Patients with Rheumatoid Arthritis and Inadequate Clinical Responses by Week 8 of Treatment
}

\author{
Edward C. Keystone, Andrew Anisfeld, Sarika Ogale, Jenny N. Devenport, and Jeffrey R. Curtis
}

\begin{abstract}
Objective. To evaluate whether patients with rheumatoid arthritis who did not respond sufficiently to tocilizumab (TCZ) plus disease-modifying antirheumatic drug (DMARD) treatment by Week 8 responded at later timepoints when continuing to take their original dose of TCZ.

Methods. In this posthoc analysis of data from phase III randomized controlled trials of inadequate responders (IR) to DMARD or tumor necrosis factor- $\alpha$ inhibitors (anti-TNF), percentages of patients meeting early response criteria were calculated by randomized treatment arm (TCZ $4 \mathrm{mg} / \mathrm{kg}$, $8 \mathrm{mg} / \mathrm{kg}$, or placebo in combination with DMARD). Percentages of patients achieving certain disease activity thresholds at later timepoints were calculated for patients who had/had not achieved response by Week 8 .

Results. In DMARD-IR early nonresponders, $29.0 \%, 17.2 \%$, and $3.7 \%$ of TCZ $8 \mathrm{mg} / \mathrm{kg}$-randomized, TCZ $4 \mathrm{mg} / \mathrm{kg}$-randomized, and placebo-randomized patients, respectively, achieved 28 -joint Disease Activity Score (DAS28) $\leq 3.2$ by Week 24. Among anti-TNF-IR patients without early response, $26.5 \%, 8.5 \%$, and $1.9 \%$ of TCZ $8 \mathrm{mg} / \mathrm{kg}$-randomized, TCZ $4 \mathrm{mg} / \mathrm{kg}$-randomized, and placebo-randomized patients, respectively, achieved DAS28 $\leq 3.2$ at Week 24 .

Conclusion. A substantial number of DMARD-IR patients taking TCZ 4 or $8 \mathrm{mg} / \mathrm{kg}$ and anti-TNF-IR patients taking TCZ $8 \mathrm{mg} / \mathrm{kg}$ who failed to respond by 8 weeks benefited from continued TCZ treatment in combination with DMARD. In contrast, the anti-TNF-IR patients without early responses who continued to take TCZ $4 \mathrm{mg} / \mathrm{kg}$ were unlikely to experience a cumulative benefit. ClinicalTrials.gov registration numbers: NCT00106548, NCT00106574, NCT00106535, NCT00106522. (First Release Jan 15 2014; J Rheumatol 2014;41:216-26; doi:10.3899/jrheum.130489)
\end{abstract}

Key Indexing Terms:

RHEUMATOID ARTHRITIS

MONOCLONAL ANTIBODIES

\section{ANTIRHEUMATIC AGENTS TREATMENT OUTCOME}

Routine measurement of disease activity using composite criteria $^{1}$ is recommended to increase the probability of favorable outcomes in patients with rheumatoid arthritis
(RA). The introduction of new biologics and disease-modifying antirheumatic drugs (DMARD) has greatly increased the number of effective therapies available to patients, but
From Mount Sinai Hospital, The Rebecca MacDonald Centre for Arthritis and Autoimmune Disease, Toronto, Ontario, Canada; US Medical Affairs-Immunology and Biometrics and Health Outcomes, Genentech, South San Francisco, California; University of Alabama at Birmingham, Division of Clinical Immunology and Rheumatology, Birmingham, Alabama, USA.

Funding for manuscript preparation was provided by F. Hoffmann-La Roche Ltd. Dr. Curtis receives support from the US National Institutes of Health (AR 053351) and has received research grants from the Agency for Healthcare Research and Quality, and consultancy fees from Abbott Laboratories, Amgen Inc., Bristol-Myers Squibb, Centocor Inc., CORRONA, Crescendo Therapeutics LLC, F. Hoffmann-La Roche Inc., Genentech, Pfizer Pharmaceuticals, and UCB. Dr. Keystone has received research grants from Abbott Laboratories, Amgen Inc., AstraZeneca Pharmaceuticals LP, Bristol-Myers Squibb, Centocor Inc.,

F. Hoffmann-La Roche Inc., Genzyme, Merck Sharp \& Dohme, Novartis Pharmaceuticals, Pfizer Pharmaceuticals, and UCB; consultancy fees from Abbott Laboratories, AstraZeneca Pharmaceuticals LP, Biotest, Bristol-Myers Squibb, Centocor Inc., F. Hoffmann-La Roche Inc., Genentech Inc., Merck Sharp \& Dohme, Nycomed, Pfizer

Pharmaceuticals, and UCB; lecture/speakers honoraria from Abbott
Laboratories, Amgen Inc., Bristol-Myers Squibb, Janssen Inc., Merck Sharp \& Dohme, Pfizer Pharmaceuticals, and UCB; board membership fees from Abbott Laboratories, AstraZeneca Pharmaceuticals LP, Biotest, Bristol-Myers Squibb, Centocor Inc., Genentech Inc., Merck Sharp \& Dohme, Nycomed, Pfizer Pharmaceuticals, and UCB; and fees for participation in data monitoring boards from F. Hoffmann-La Roche Inc. Drs. Anisfeld, Ogale, and Devenport are employees of Genentech, a member of the Roche group.

E.C. Keystone, MD, FRCPC, Mount Sinai Hospital, The Rebecca MacDonald Centre for Arthritis and Autoimmune Disease; A. Anisfeld, PhD, US Medical Affairs-Immunology; S. Ogale, PhD; J.N. Devenport, PhD, Biometrics and Health Outcomes, Genentech; J.R. Curtis, MD, MS, $M P H$, University of Alabama at Birmingham, Division of Clinical Immunology and Rheumatology.

Address correspondence to Dr. E.C. Keystone, Professor of Medicine, University of Toronto Faculty of Medicine, 1 King's College Circle, Medical Sciences Building, Room 2109, Toronto, Ontario M5S 1A8, Canada.E-mail: edkeystone@mtsinai.on.ca

Full Release Article. For details see Reprints/Permissions at jrheum.org Accepted for publication October 8, 2013. 
not all patients will respond adequately to any given therapy. Identifying patients not responding to a given mechanism of action is critical to ensure that therapy can be modified to alleviate symptoms and prevent further disease progression. However, the length of time necessary to observe a response to any given therapy varies, and some patients who do not respond early may respond with additional exposure to that same therapy. Because there is no guarantee that switching to a different therapy will lead to a greater likelihood of response, it is important to determine whether sufficient time has been dedicated to a given therapeutic strategy before deeming the patient an inadequate responder (IR).

Analyses of patients treated with tumor necrosis factor inhibitors (anti-TNF) have indicated that a proportion of patients with early inadequate responses will achieve more robust responses with continued treatment. In the Trial of Etanercept and Methotrexate with Radiographic Patient Outcomes (TEMPO), a significant proportion of non-responders and partial responders at Week 12 achieved good clinical response or improved overall clinical response at Week 24. The investigators concluded that discontinuing anti-TNF therapy at Week 12 may be premature in some patients $^{2}$. Indeed, in $15 \%$ to $20 \%$ of patients, more than 12 weeks may be needed to assess response to an anti-TNF agent $^{3}$.

Tocilizumab (TCZ) is a humanized monoclonal antibody that binds to membrane-bound and soluble forms of the interleukin 6 (IL-6) receptor, thereby inhibiting IL-6-mediated signaling and its proinflammatory effects. The efficacy and safety of TCZ in patients with RA were demonstrated in 5 pivotal phase III randomized controlled trials (RCT) ${ }^{4,5,6,7,8}$. Improvements in mean Disease Activity Score using 28 joints (DAS28) and patient-reported outcomes occurred as early as 4 weeks after treatment ${ }^{4,5,9,10}$. Evaluation of specific patient-level response criteria over time (e.g., DAS28 < 2.6, DAS28 <3.2) revealed increasing numbers of patients achieving these criteria throughout the 24-week course of the studies. Similar observations have been made with patient-reported disease assessments in the Rapid Onset and Systemic Efficacy (ROSE) study.

Our present analysis evaluated whether patients treated with TCZ + DMARD across the TCZ phase III pivotal program who did not achieve certain indicators of efficacy by Week 8 achieved clinically relevant responses at later timepoints with continued treatment with initial doses of TCZ.

\section{MATERIALS AND METHODS}

Patient population. Data from patients in 4 pivotal phase III RCT were included in this analysis (ClinicalTrials.gov registration numbers: NCT00106548, NCT00106574, NCT00106535, NCT00106522). In 3 trials, DMARD-IR patients received TCZ (4 or $8 \mathrm{mg} / \mathrm{kg}^{5,6}$ or $8 \mathrm{mg} / \mathrm{kg}^{7}$ ) or placebo every 4 weeks plus weekly methotrexate (MTX)/DMARD. Data from the 3 DMARD-IR trials were pooled because of the similar patient characteristics and response rates observed across trials. In 1 trial ${ }^{4}$, patients with previous inadequate responses to anti-TNF agents (anti-TNF-IR) received TCZ $4 \mathrm{mg} / \mathrm{kg}$, TCZ $8 \mathrm{mg} / \mathrm{kg}$, or placebo every 4 weeks plus weekly MTX. In all 4 clinical trials, the primary outcomes were assessed at Week 24. Rescue therapy was allowed in patients not responding to randomized treatment through criteria that were specific for each study, beginning at Week 16. Because exposure to previous biologics has a documented effect on the probability of response to successive therapies, the analyses were completed separately for IR patients to DMARD and for those who also had inadequate responses to anti-TNF therapy $4,11,12,13$.

Statistical analyses. In these posthoc exploratory analyses, outcomes were analyzed based on stratification by randomized treatment group and on whether early response criteria were met (yes/no). Outcomes of interest were key thresholds of disease activity: DAS28 $\leq 3.2$, DAS28 $<2.6$, clinical disease activity index $(\mathrm{CDAI}) \leq 10$, and simplified disease activity index $(\mathrm{SDAI}) \leq 11$. Multiple early response criteria were used, including the disease activity thresholds defined as outcomes themselves and the alternative criteria of 50\% improvement from baseline in swollen joint count (SJC) or Routine Assessment of Patient Index Data (RAPID) good/moderate response ${ }^{14}$. Alternative response criteria - improvements in SJC66 and RAPID3 - were assessed because the composite disease activity outcomes are not always used in clinical practice. "Early" was defined as "by Week 8," which meant that a patient was classified as showing an early response if the criteria were met at Week 4 , Week 8 , or both.

Cumulative benefit of continued treatment was evaluated by analyzing the conditional response rates on outcomes over time, focusing particularly on patients who had not met early response criteria. First, response rates for each of the disease activity threshold outcomes were analyzed every 4 weeks from Week 12 through Week 24 for patients who had not yet achieved them by Week 8 . Second, response rates for the disease activity threshold outcomes were analyzed at Week 24 for patients who had not achieved the alternative early response criteria by Week 8 .

Performance of the alternative early response criteria as predictors of Week 24 outcomes was evaluated by calculating the sensitivity (percentage of Week 24 responders correctly identified as such by Week 8), specificity (percentage of Week 24 nonresponders correctly identified as such by Week 8 ), positive predictive value (PPV), and negative predictive value (NPV; Appendix 1). As a sensitivity analysis, the performance of other possible cutoffs and the overall accuracy of SJC66 improvement by Week 8 for predicting Week 24 outcomes were explored by constructing the receiver-operating characteristic (ROC) curve and calculating the area under the curve (AUC). The AUC of the ROC curve ranges between 0 and 1 , where higher AUC values indicate greater discrimination/accuracy of prediction (e.g., 0.5 chance level of prediction, and 1.0 perfectly accurate prediction $)^{15}$.

All analyses were based on the intent-to-treat population (patients receiving $\geq 1$ dose of study medication and having $\geq 1$ postbaseline assessment). Missing joint counts were imputed using last observation carried forward. For each categorical disease activity outcome, patients who received rescue therapy, withdrew, or had missing data were included as nonresponders.

\section{RESULTS}

Demographic characteristics, baseline characteristics, and patient disposition throughout each of the RCT for DMARD-IR and anti-TNF-IR patients were reported previously ${ }^{4,5,6,7}$. Demographic and baseline characteristics were similar across treatment groups. In addition, there were no apparent associations between demographics or baseline characteristics for patients who did or did not meet early response criteria (Appendix 2 and 3).

Response rates by Week 8 were higher among TCZ-treated than placebo-treated patients in DMARD-IR

Personal non-commercial use only. The Journal of Rheumatology Copyright (c) 2014. All rights reserved. 
and anti-TNF-IR studies for all disease activity outcomes (Figure 1).

Cumulative benefit of continued treatment for patients not achieving disease activity thresholds early. In the DMARD-IR population, $97.3 \%$ (983/1010), $85.6 \%$ (524/612), and 72.5\% (1019/1406) of placebo-treated, TCZ

A

\begin{tabular}{|c|c|c|c|}
\hline DMARD-IR population & Placebo + DMARD & TCZ 4 mg/kg + DMARD & TCZ $8 \mathrm{mg} / \mathrm{kg}$ + DMARD \\
\hline & $\begin{array}{l}\square \text { Responders } \\
\text { Nonresponders }\end{array}$ & $\begin{array}{l}\square \text { Responders } \\
\text { Q Nonresponders }\end{array}$ & $\begin{array}{l}\square \text { Responders } \\
\text { Q Nonresponders }\end{array}$ \\
\hline
\end{tabular}

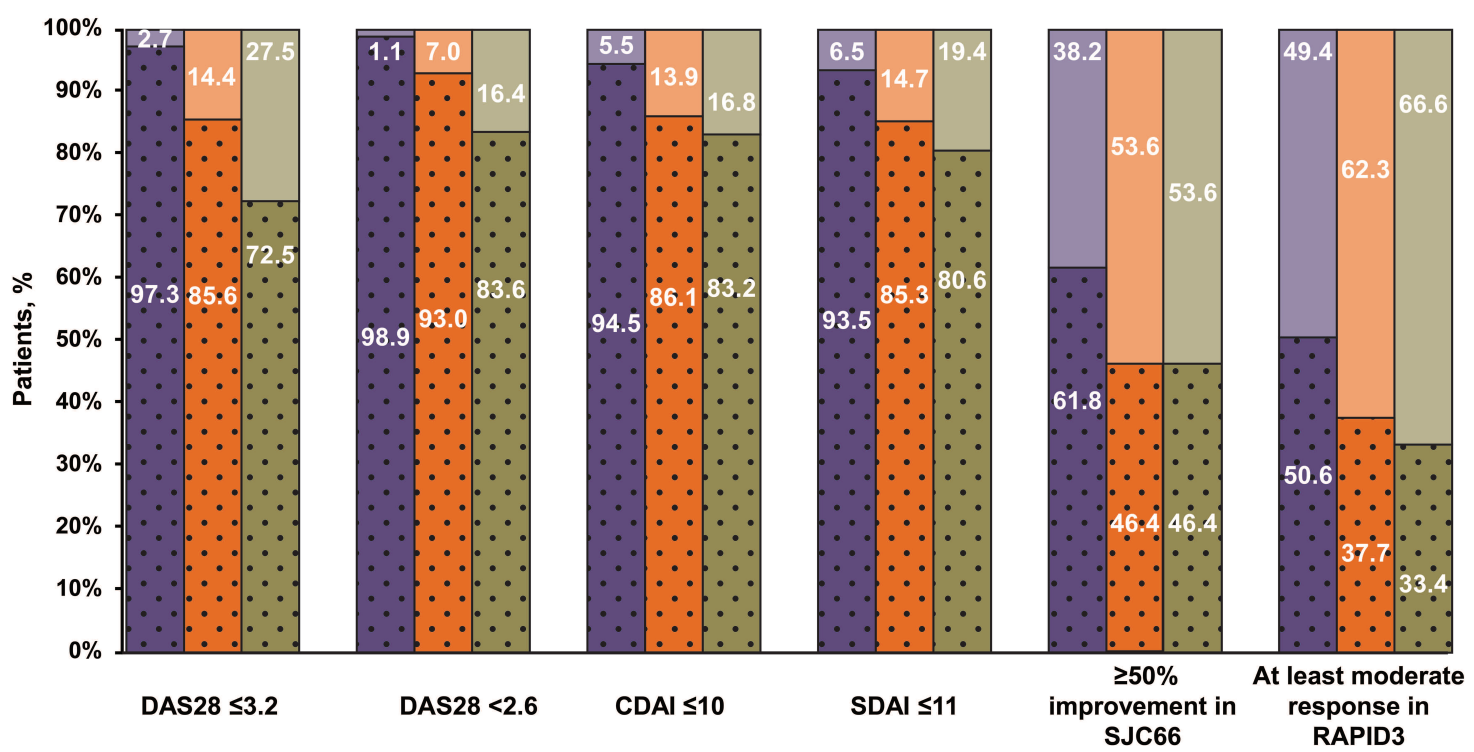

B

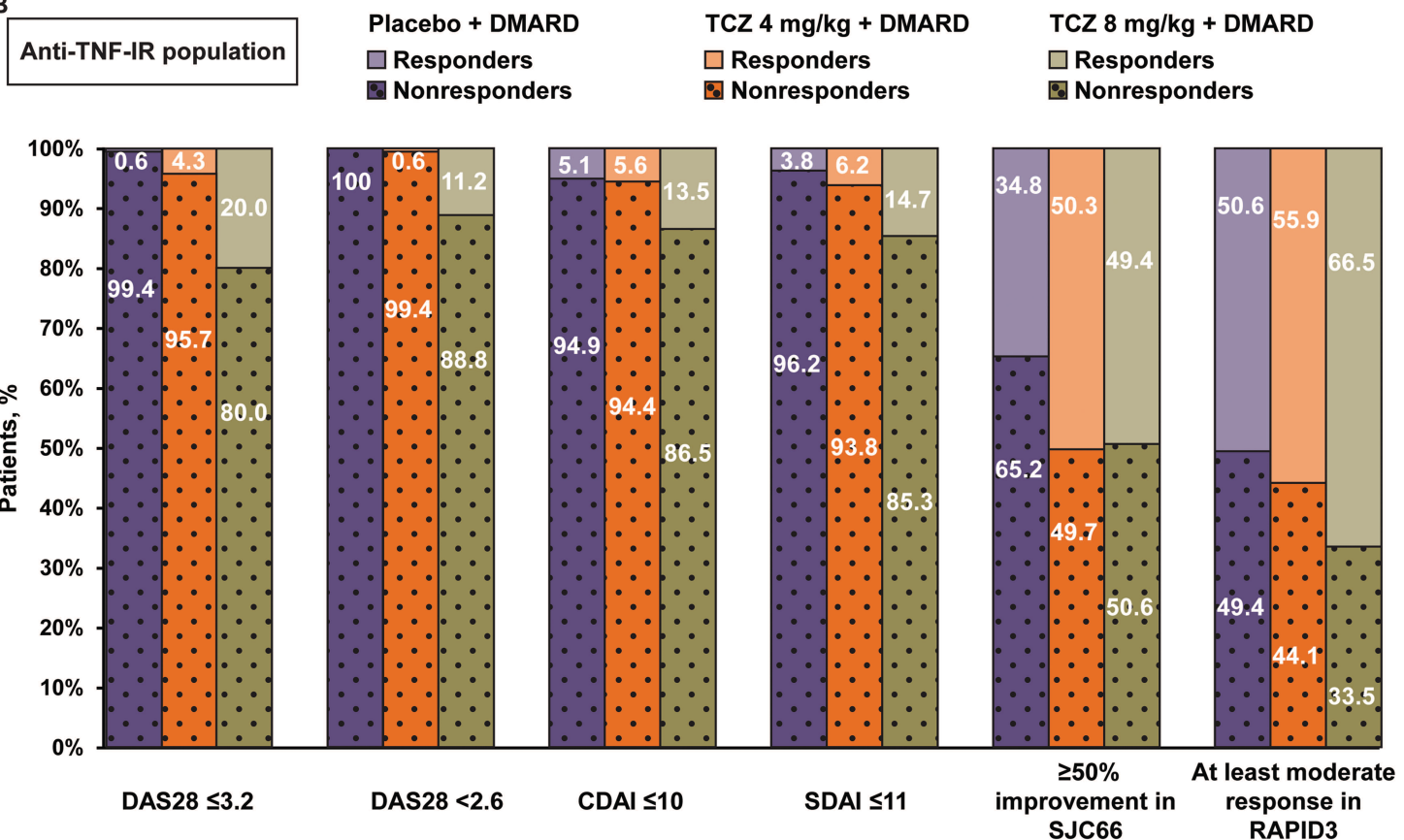

Figure 1. Response rates by Week 8 in the (A) DMARD-IR anti-TNF-IR population and (B) the anti-TNF-IR population. CDAI: Clinical Disease Activity Index; DAS28: Disease Activity Score using 28 joints; DMARD: disease-modifying antirheumatic drug; DMARD-IR: DMARD inadequate response; RAPID3: Routine Assessment of Patient Index Data 3; SDAI: Simplified Disease Activity Index; SJC66: swollen joint count based on 66 joints; anti-TNF-IR: tumor necrosis factor- $\alpha$ inhibitor inadequate response; TCZ: tocilizumab.

Personal non-commercial use only. The Journal of Rheumatology Copyright @ 2014 . All rights reserved. 
$4 \mathrm{mg} / \mathrm{kg}$-treated, and TCZ $8 \mathrm{mg} / \mathrm{kg}$-treated patients, respectively, failed to achieve DAS2 $8 \leq 3.2$ by Week 8 (Figure 1A). Of those, $17.2 \%$ and $29.0 \%$ of TCZ $4 \mathrm{mg} / \mathrm{kg}$-treated and $8 \mathrm{mg} / \mathrm{kg}$-treated patients, respectively, versus $3.7 \%$ of placebo-treated patients went on to achieve DAS28 $\leq 3.2$ at Week 24 (Figure 2A). Similar trends were observed for DAS28 $<2.6$ (Figure 2B), CDAI $\leq 10$ (Figure 2C), and $\mathrm{SDAI} \leq 11$ (Figure 2D).

A similar pattern was observed when noncomposite
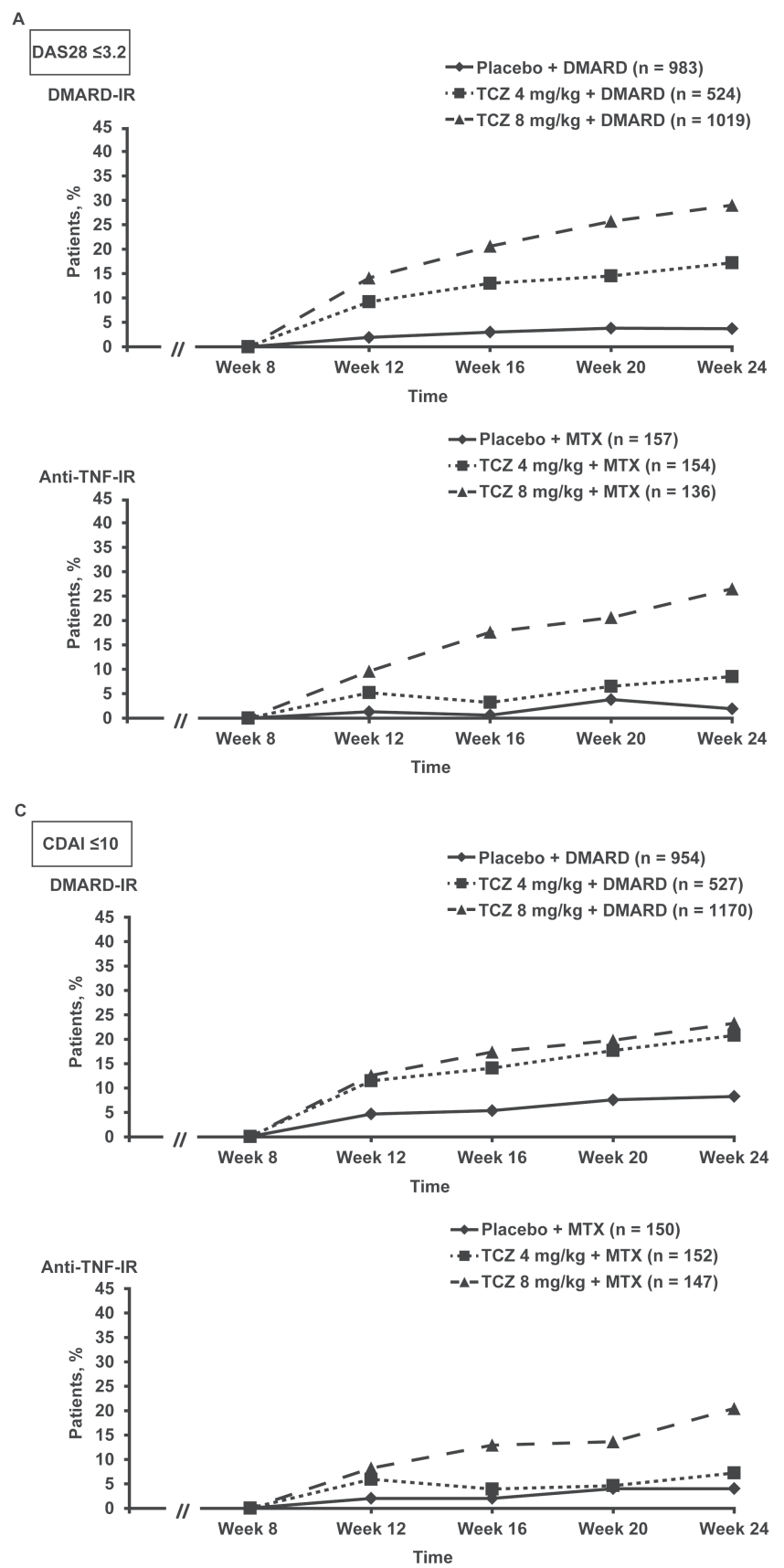

measures (SJC $<50 \%$, no RAPID3 moderate) were used to classify patients as nonresponders by Week 8 . As shown in Figure 1A, 61.8\% (624/1010), 46.4\% (284/612), and 46.4\% (652/1406) of placebo-treated, TCZ $4 \mathrm{mg} / \mathrm{kg}$-treated, and TCZ $8 \mathrm{mg} / \mathrm{kg}$-treated patients, respectively, had not achieved $\geq 50 \%$ improvement in SJC66 by Week 8. Among these patients, $2 \%, 15 \%$, and $28 \%$, respectively, went on to achieve DAS28 $\leq 3.2$ at Week 24 , whereas $1 \%, 6 \%$, and $16 \%$, respectively, achieved DAS $<2.6$ at Week 24 with

B
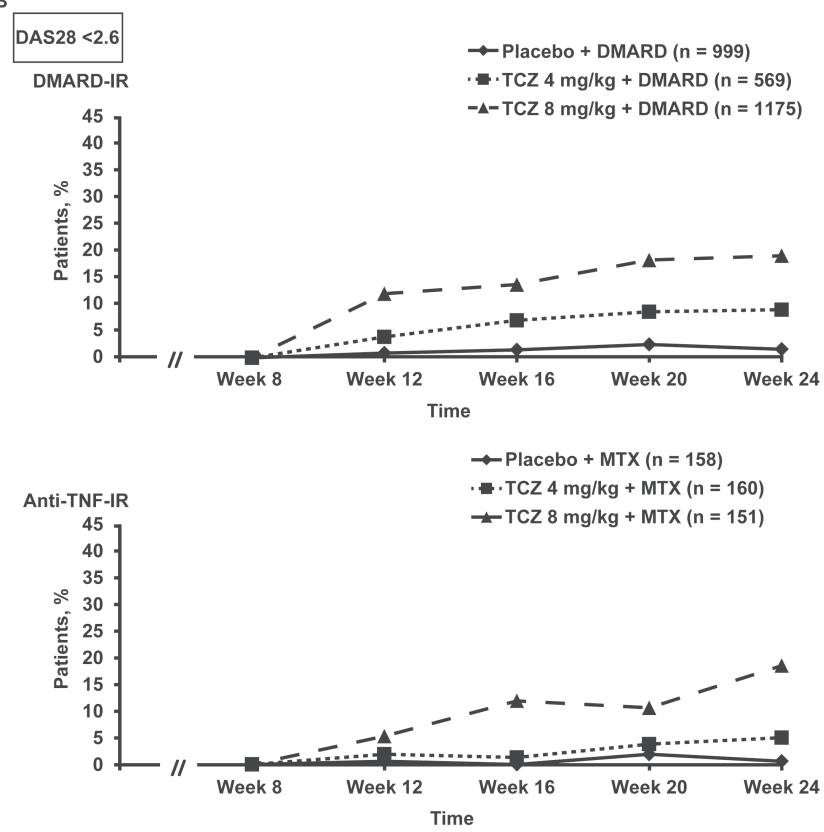

D
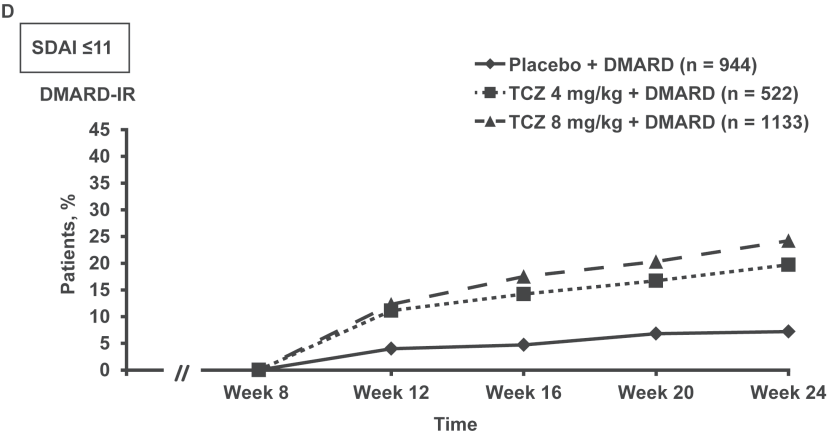

$\rightarrow$ Placebo + MTX $(n=152)$

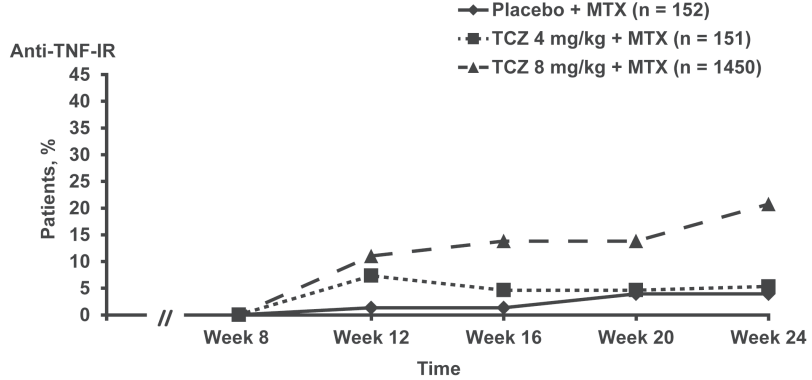

Figure 2. Percentages of DMARD-IR and anti-TNF-IR patients who did not achieve outcomes by Week 8 but achieved them at subsequent visits. (A) DAS28 $\leq 3.2$, (B) DAS28 <2.6, (C) CDAI $\leq 10$, and (D) SDAI $\leq 11$ at each visit given no response on the same outcomes by Week 8 . CDAI: Clinical Disease Activity Index; DAS28: Disease Activity Score using 28 joints; DMARD: disease-modifying antirheumatic drug; DMARD-IR: DMARD inadequate response; MTX: methotrexate; SDAI: Simplified Disease Activity Index; anti-TNF-IR: tumor necrosis factor- $\alpha$ inhibitor inadequate response; TCZ: tocilizumab. 
continued treatment on their initial TCZ dose (Table 1, Figure 3A). Rates for CDAI $\leq 10$ and $\mathrm{SDAI} \leq 11$ at Week 24 are shown (Table 1, Figure 3A).

Proportions of patients who did not achieve at least moderate RAPID3 responses by Week 8 were $50.6 \%$ $(511 / 1010), 37.7 \%(231 / 612)$, and $33.4 \%(469 / 1406)$ in the placebo-treated, TCZ $4 \mathrm{mg} / \mathrm{kg}$-treated, and TCZ 8 $\mathrm{mg} / \mathrm{kg}$-treated groups, respectively (Figure 1). Among those patients, $16 \%$ (and $27 \%$ of those receiving TCZ $4 \mathrm{mg} / \mathrm{kg}$ and $8 \mathrm{mg} / \mathrm{kg}$, respectively) achieved DAS28 $\leq 3.2$ at Week 24 versus $3 \%$ of those receiving placebo. Respective rates for $\mathrm{DAS} 28<2.6, \mathrm{CDAI} \leq 10$, and $\mathrm{SDAI} \leq 11$ at Week 24 were

Table 1. Performance characteristics of early response criteria for disease activity outcomes at Week 24 (DMARD-IR population).

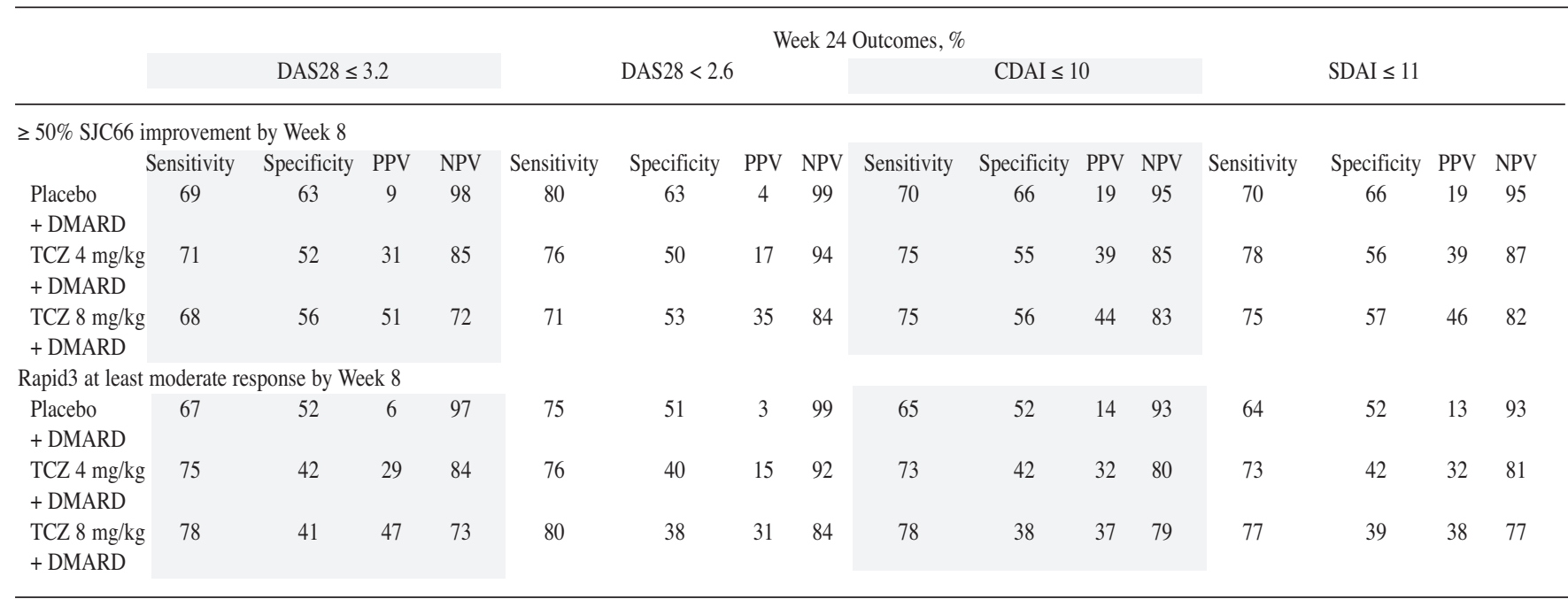

CDAI: Clinical Disease Activity Index; DAS28: Disease Activity Score using 28 joints; DMARD-IR: DMARD inadequate response; NPV: negative predictive value; PPV: positive predictive value; RAPID3: Routine Assessment of Patient Index Data 3; SDAI: Simplified Disease Activity Index; SJC66: swollen joint count based on 66 joints; TCZ: tocilizumab.

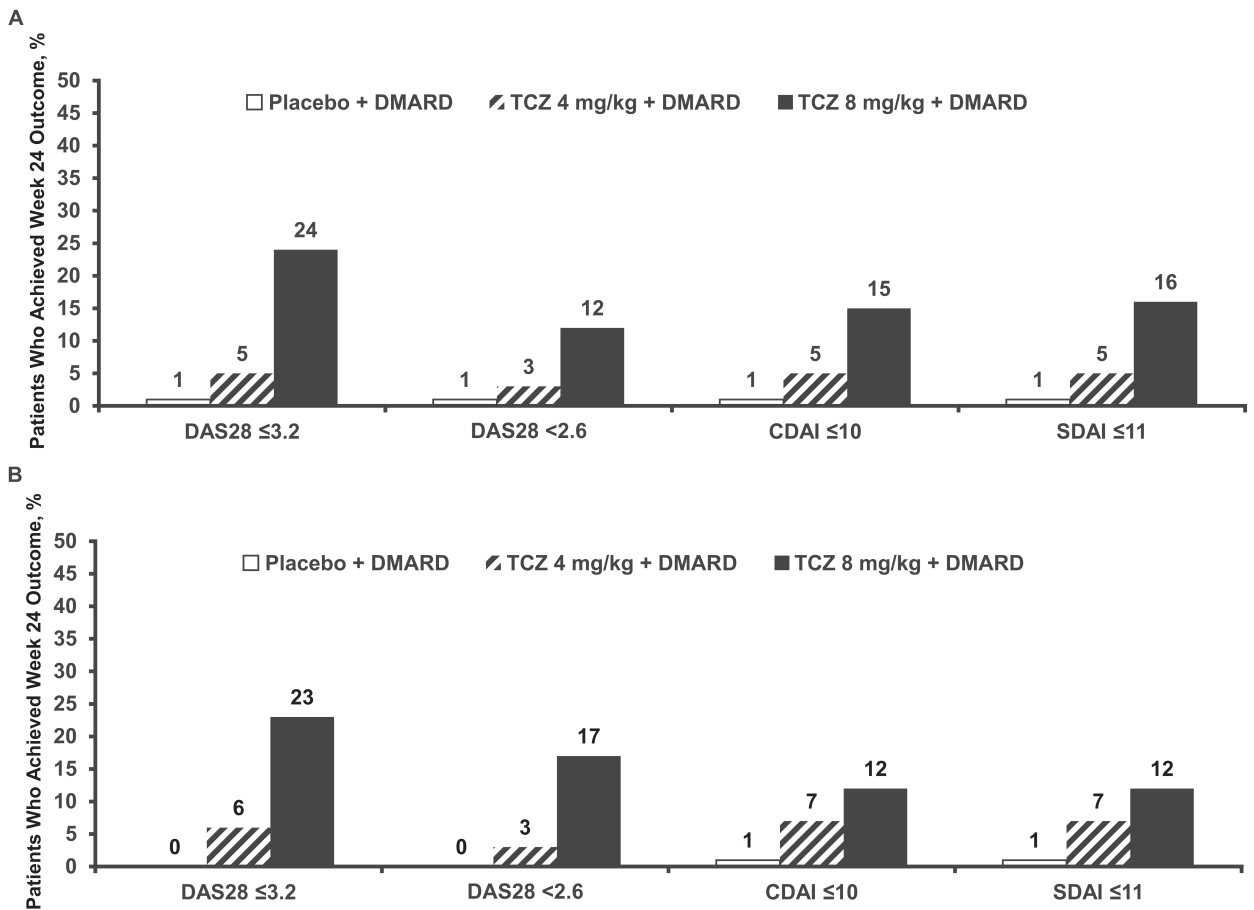

Figure 3. Week 24 disease activity outcomes among DMARD-IR patients who did not respond by Week 8 , defined as (A) $\geq 50 \%$ SJC66, or (B) at least moderate improvement in RAPID3. CDAI: Clinical Disease Activity Index; DAS28: Disease Activity Score using 28 joints; DMARD: disease-modifying antirheumatic drug; DMARD-IR: DMARD inadequate response; RAPID3: Routine Assessment of Patient Index Data 3; SDAI: Simplified Disease Activity Index; SJC66: swollen joint count based on 66 joints; TCZ: tocilizumab. 
similar to those observed when the SJC cutoff was used (Table 1, Figure 3B).

Among anti-TNF-IR patients classified as early nonresponders, greater differences were observed between TCZ doses in achievement of Week 24 disease activity outcomes. Proportions of patients who failed to achieve DAS $\leq 3.2$ by Week 8 were $99.4 \%$ (157/158), 95.7\% (154/161), and 80.0\% (136/170) in the placebo-treated, TCZ $4 \mathrm{mg} / \mathrm{kg}$-treated, and TCZ $8 \mathrm{mg} / \mathrm{kg}$-treated groups, respectively (Figure 1B). Among those, the proportion of patients achieving DAS28 $\leq$ 3.2 at Week 24 while receiving TCZ $8 \mathrm{mg} / \mathrm{kg}$ was $26.5 \%$. In contrast, response from further exposure to TCZ $4 \mathrm{mg} / \mathrm{kg}$ $(8.5 \%)$ was less frequent, although still numerically higher, than placebo (1.9\%; Figure 2A). Similar trends were observed for DAS28 $<2.6$ (Figure 2B), CDAI $\leq 10$ (Figure $2 \mathrm{C}$ ), and SDAI $\leq 11$ (Figure 2D).

As in the DMARD-IR population, similar trends were noted when SJC and RAPID3 criteria were used to define nonresponders by Week 8 . In the anti-TNF-IR population, $65.2 \%$ (103/158), 49.7\% (80/161), and 50.6\% (86/170) of placebo-treated, TCZ $4 \mathrm{mg} / \mathrm{kg}$-treated, and TCZ 8 $\mathrm{mg} / \mathrm{kg}$-treated patients, respectively, did not achieve $\geq 50 \%$ improvement in SJC66 by Week 8 (Figure 1B). Of those receiving TCZ $8 \mathrm{mg} / \mathrm{kg}, 24 \%$ of patients not responding by Week 8 went on to achieve DAS $\leq 3.2$ at Week 24 compared with only $5 \%$ and $1 \%$ of those treated with TCZ $4 \mathrm{mg} / \mathrm{kg}$ and placebo. Respective rates for the other disease activity measures at Week 24 exhibited similar patterns (Table 2; Figure 4A).

Using RAPID3 moderate response as the criterion for early response, $49.4 \%$ (78/158), $44.1 \%$ (71/161), and 33.5\% (57/170) of placebo-treated, TCZ $4 \mathrm{mg} / \mathrm{kg}$-treated, and TCZ
$8 \mathrm{mg} / \mathrm{kg}$-treated anti-TNF-IR patients, respectively, did not achieve a response by Week 8 (Figure 1B). Twenty-three percent of those continuing TCZ $8 \mathrm{mg} / \mathrm{kg}$ compared with $6 \%$ of those receiving $4 \mathrm{mg} / \mathrm{kg}$ and none of those receiving placebo went on to achieve DAS $\leq 3.2$ at Week 24 (Table 2, Figure 4B).

Performance characteristics for early indicators of efficacy by Week 8 as predictors of Week 24 outcomes. Performance characteristics (sensitivity, specificity, NPV, and PPV) for the early indicators of efficacy are presented in Tables 1 and 2. In the DMARD-IR and anti-TNF-IR populations, both early indicators of efficacy had moderate ability to correctly identify patients treated with TCZ who achieved disease activity thresholds at Week 24, with SJC66 sensitivities ranging from $67 \%$ to $79 \%$ and RAPID3 sensitivities ranging from $67 \%$ to $86 \%$ for the 2 TCZ doses. Overall, NPV for DAS28 $\leq 3.2$ were in the $72 \%$ to $85 \%$ range (except for the anti-TNF-IR 4-mg/kg group, whose NPV were 94\%-95\%), indicating that these cutoffs failed to correctly classify up to $28 \%$ of patients who did not achieve early response but later achieved Week 24 clinical response with continued treatment on their initial dose.

Performance characteristics of all possible cutoffs for the percentage SJC66 improvement by Week 8 were evaluated to see whether other threshold values would better predict Week 24 disease activity outcomes. Accuracy of Week 8 percentage SJC66 improvement at predicting Week 24 outcomes, as measured by AUC of the ROC curves for the entire range of cutoffs for percentage SJC66 improvement, ranged from 0.65 to 0.74 ( 0.5 : chance level of prediction). Based on the intersection of sensitivity and specificity curves (not shown), accuracy of prediction for Week 24

Table 2. Performance characteristics of early response criteria for disease activity outcomes at Week 24 (anti-TNF-IR population).

\begin{tabular}{|c|c|c|c|c|c|c|c|c|c|c|c|c|c|c|c|c|}
\hline & \multicolumn{16}{|c|}{ Week 24 Outcomes, $\%$} \\
\hline & \multicolumn{4}{|c|}{ DAS28 $\leq 3.2$} & \multicolumn{4}{|c|}{ DAS $28<2.6$} & \multicolumn{4}{|c|}{$\mathrm{CDAI} \leq 10$} & \multicolumn{4}{|c|}{$\mathrm{SDAI} \leq 11$} \\
\hline \multicolumn{17}{|c|}{$\geq 50 \%$ SJC66 improvement by Week 8} \\
\hline $\begin{array}{l}\text { Placebo } \\
\text { + DMARD }\end{array}$ & $\begin{array}{c}\text { Sens. } \\
67\end{array}$ & $\begin{array}{l}\text { Spec. } \\
66\end{array}$ & $\begin{array}{c}\text { PPV } \\
4\end{array}$ & $\begin{array}{c}\text { NPV } \\
99\end{array}$ & $\begin{array}{c}\text { Sens. } \\
0\end{array}$ & $\begin{array}{l}\text { Spec. } \\
65\end{array}$ & $\begin{array}{c}\text { PPV } \\
0\end{array}$ & $\begin{array}{c}\text { NPV } \\
99\end{array}$ & $\begin{array}{l}\text { Sens. } \\
88\end{array}$ & $\begin{array}{l}\text { Spec. } \\
68\end{array}$ & $\begin{array}{c}\text { PPV } \\
13\end{array}$ & $\begin{array}{c}\text { NPV } \\
99\end{array}$ & $\begin{array}{c}\text { Sens. } \\
88\end{array}$ & $\begin{array}{c}\text { Spec. } \\
68\end{array}$ & $\begin{array}{c}\text { PPV } \\
13\end{array}$ & $\begin{array}{c}\text { NPV } \\
99\end{array}$ \\
\hline $\begin{array}{l}\text { TCZ } 4 \mathrm{mg} / \mathrm{kg} \\
+ \text { DMARD }\end{array}$ & 75 & 52 & 15 & 95 & 75 & 51 & 7 & 98 & 77 & 53 & 16 & 95 & 73 & 52 & 14 & 95 \\
\hline $\begin{array}{l}\text { TCZ } 8 \mathrm{mg} / \mathrm{kg} \\
\text { + DMARD }\end{array}$ & 67 & 61 & 50 & 76 & 73 & 57 & 32 & 88 & 73 & 60 & 42 & 85 & 71 & 60 & 42 & 84 \\
\hline \multicolumn{17}{|c|}{ Rapid3 at least moderate response by Week 8} \\
\hline $\begin{array}{l}\text { Placebo } \\
\text { + DMARD }\end{array}$ & 100 & 50 & 4 & 100 & 100 & 50 & 1 & 100 & 88 & 51 & 9 & 99 & 88 & 51 & 9 & 99 \\
\hline $\begin{array}{l}\mathrm{TCZ} 4 \mathrm{mg} / \mathrm{kg} \\
\text { + DMARD }\end{array}$ & 75 & 46 & 13 & 94 & 75 & 45 & 7 & 97 & 71 & 46 & 13 & 93 & 67 & 45 & 11 & 93 \\
\hline $\begin{array}{l}\mathrm{TCZ} 8 \mathrm{mg} / \mathrm{kg} \\
\text { + DMARD }\end{array}$ & 79 & 41 & 44 & 77 & 73 & 35 & 24 & 83 & 85 & 41 & 36 & 88 & 86 & 41 & 37 & 88 \\
\hline
\end{tabular}

CDAI: Clinical Disease Activity Index; DAS28: Disease Activity Score using 28 joints; DMARD: disease-modifying antirheumatic drug; NPV: negative predictive value; PPV: positive predictive value; RAPID3: Routine Assessment of Patient Index Data 3; SDAI: Simplified Disease Activity Index; Sens.: sensitivity; Spec.: specificity; SJC66: swollen joint count based on 66 joints; anti-TNF-IR: tumor necrosis factor- $\alpha$ inhibitor inadequate response; TCZ: tocilizumab.

Personal non-commercial use only. The Journal of Rheumatology Copyright @ 2014 . All rights reserved. 


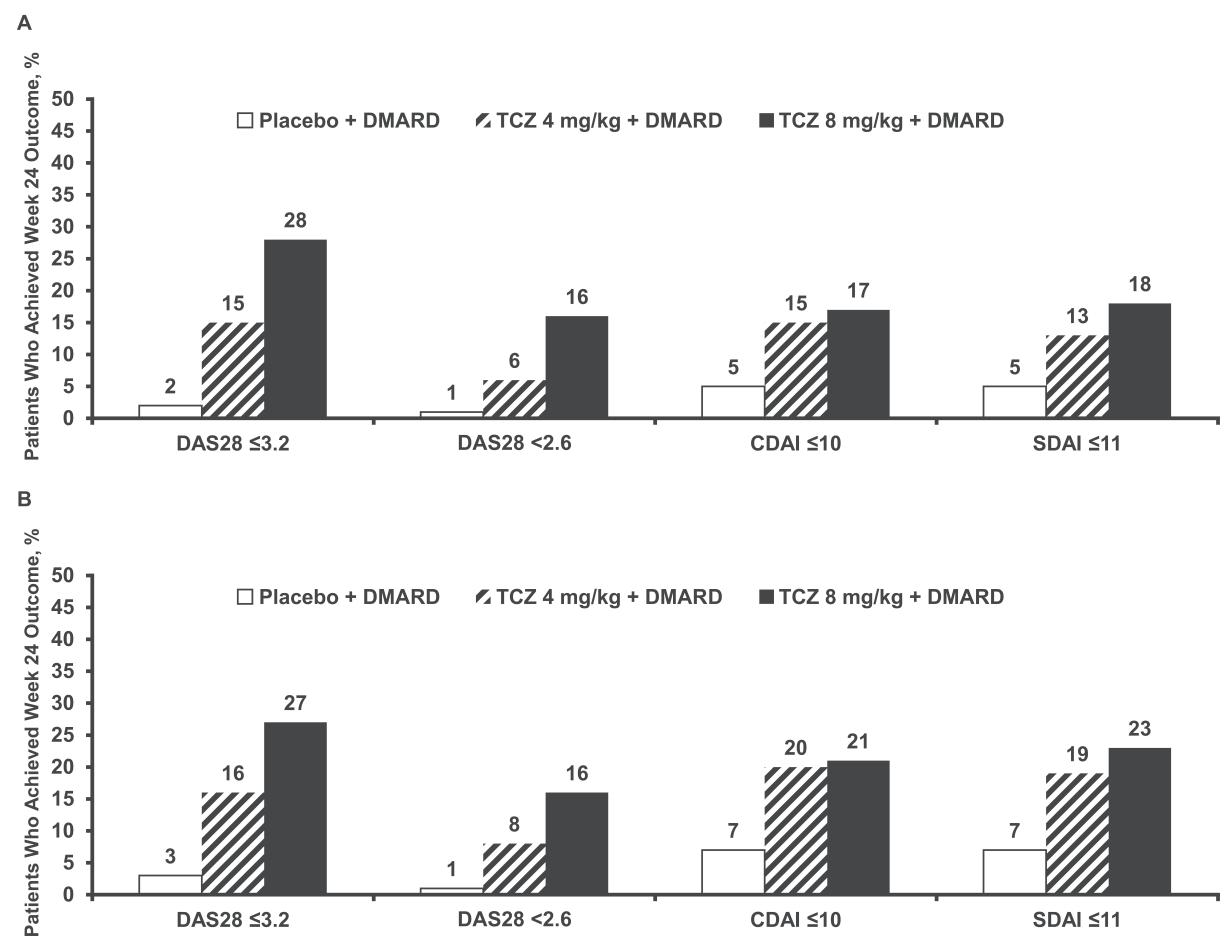

Figure 4 . Week 24 disease activity outcome in anti-TNF-IR patients who did not respond by Week 8 , defined as $(\mathrm{A}) \geq 50 \%$ SJC66, or (B) at least moderate improvement in RAPID3. CDAI: Clinical Disease Activity Index; DAS28: Disease Activity Score using 28 joints; DMARD: disease-modifying antirheumatic drug; RAPID3: Routine Assessment of Patient Index Data 3; SDAI: Simplified Disease Activity Index; SJC66: swollen joint count based on 66 joints; anti-TNF-IR: tumor necrosis factor- $\alpha$ inhibitor inadequate response; TCZ: tocilizumab.

outcomes was maximized using thresholds of $50 \%$ to $60 \%$ improvement in SJC66 by Week 8. These findings indicate that improvement in SJC66 would not have predicted later disease activity outcomes better if a different threshold had been selected.

\section{DISCUSSION}

Herein, the cumulative benefit of continuing initial treatment doses of TCZ plus a DMARD was evaluated using several approaches. First, conditional response rates of several composite disease activity outcomes (DAS28, CDAI, SDAI) were evaluated at later timepoints for patients who had not achieved them by Week 8 . Results showed that some of these early "nonresponder" patients went on to achieve responses at later timepoints - in other words, they experienced additional benefit. The frequency of this achievement was more common in DMARD-IR patients receiving either dose of TCZ. This suggests that some of these early nonresponders might have benefited from continued treatment beyond Week 8; therefore, reassessment of early response and continued benefit at a different timepoint (Week 12) might have been warranted in these patients. However, in the group of patients who previously had inadequate responses to anti-TNF, few receiving TCZ 4 $\mathrm{mg} / \mathrm{kg}$ who did not respond by Week 8 experienced cumulative benefit over time ( $8.5 \%$ achieved DAS28 $\leq 3.2$ at Week 24), suggesting limited value in continuing therapy at the same TCZ dose if early response by 8 weeks is not observed.

The question of cumulative benefit is related to prediction of response - specifically, does early response predict later response? The answer to this question has important implications for treatment: i.e., how much response is adequate and when should that determination be made? The results of the current study show that although there is some association between early response measured at Week 8 and later response at Week 24 for the same endpoint (e.g., DAS28 $\leq 3.2$ by Week 8 and at Week 24), it is not perfect; there were "false negatives" and "false positives." This was true regardless of the early response criteria used (DAS28 $\leq 3.2$, CDAI $\leq 10$, SDAI $\leq 11$, improvement in SJC or improvement in RAPID3). Sensitivities for the DMARD-IR and anti-TNF-IR populations ranged from $67 \%$ to $86 \%$, suggesting that a substantial proportion of Week 24 responders were not correctly classified based on their Week 8 nonresponses according to SJC and RAPID3 criteria. Further review of the baseline and demographic characteristics of early responders/nonresponders showed that the groups were highly similar (Appendix 2 and 3). Thus, a clear predictor or set of

Personal non-commercial use only. The Journal of Rheumatology Copyright $\odot$ 2014. All rights reserved. 
predictors to identify treatment responders did not emerge from our analysis, and this remains a topic for future research.

Our analysis is limited by intrinsic study design elements, including the mandated rescue therapy and total time of patient observation. Rescue therapy was uniformly mandated by protocol beginning at Week 16 if patients had not achieved at least 50\% improvement in swollen and tender joints, which limited our ability to investigate the probability of achieving a cumulative benefit across the full spectrum of randomly assigned patients. In designing the current analysis, the assumption was made that patients receiving rescue therapy would not have achieved a given endpoint while taking their originally assigned therapy; therefore, those patients were classified as nonresponders. However, it is theoretically possible that some would have experienced cumulative benefit if they continued the same dose. Because of the mandated rescue therapy, a direct comparison of rescue therapy versus continued therapy was not feasible.

Despite recent recommendations to routinely monitor disease activity using a composite outcome, such monitoring is not uniform across rheumatology practice. Therefore, analyses were also conducted using alternative criteria (SJC66, which does not require laboratory assessments, and RAPID3, which does not require joint counts or laboratory assessments) that might be simpler to use in different clinical settings. All the studies included in this analysis were 24 weeks in length. Week 8 was used as the timepoint to assess early response. Anecdotal evidence suggests that some physicians assess, and possibly alter, a patient's treatment earlier than Week 12, which is the assessment timepoint recommended in treat-to-target guidelines ${ }^{16}$. A later timepoint ( $>8$ weeks) might have provided better accuracy of prediction. However, given that patients in these trials could have received rescue therapy as early as Week 16, adequate observation could not have occurred before rescue, had the Week 12 timepoint been used. Treat-to-target guidelines recommend assessing disease activity with an objective assessment tool every 12 weeks and making a change in treatment if patients have not reached an agreed goal. Implicit in these recommendations is that the probability of response to the modified treatment is more favorable than continuing the previous therapy. The results presented here suggest that a proportion of patients will achieve established targets of disease activity in spite of not having achieved those responses by Week 8 . Whether the findings would hold true if Week 12 assessments were used to define nonresponse was not addressed in our analysis because of the limitations discussed, but is worthy of additional study.

Dosing recommendations for TCZ in the United States and Canada differ from those for the rest of the world; the recommended starting dose in the United States and Canada is $4 \mathrm{mg} / \mathrm{kg}$, with escalation to $8 \mathrm{mg} / \mathrm{kg}$ based on clinical response. The results presented here suggest that the treatment history and associated patient characteristics may influence the probability of a cumulative benefit in patients who have not achieved early responses. Patients in the anti-TNF-IR population, who in this analysis had longer durations of disease and previously underwent more RA treatments than did the DMARD-IR groups, were unlikely to achieve a response with continued exposure to the same dose. Data from Curtis, et $a l^{17}$ showed that a proportion of patients randomly assigned to TCZ $4 \mathrm{mg} / \mathrm{kg}$ who received rescue therapy of TCZ $8 \mathrm{mg} / \mathrm{kg}$ experienced an additional benefit from the increased dose. Together, these data suggest that individual patient characteristics should be taken into account when assessing dose escalation in patients who do not achieve early response to the $4-\mathrm{mg} / \mathrm{kg}$ dose. The characteristics of the studies examined here did not permit direct comparison of the relative benefit of cumulative exposure to the initial dose with escalation of dose in patients who initiated treatment with TCZ $4 \mathrm{mg} / \mathrm{kg}$. Addressing this gap is a relevant question for future study.

These data suggest that anti-TNF-IR patients who receive TCZ $4 \mathrm{mg} / \mathrm{kg}$ but who do not respond by Week 8 are unlikely to respond to this dose by Week 24; clinicians may consider changing treatment (e.g., escalating from $4 \mathrm{mg} / \mathrm{kg}$ to $8 \mathrm{mg} / \mathrm{kg}$ in anti-TNF-IR patients who do not achieve optimal clinical response by Week 8). On the other hand, DMARD-IR patients starting with TCZ 4 or $8 \mathrm{mg} / \mathrm{kg}$ and anti-TNF-IR patients starting with TCZ $8 \mathrm{mg} / \mathrm{kg}$ may benefit from continuing TCZ treatment, even if they do not show at least 50\% improvement in SJC66 by Week 8. Future research should focus on evaluating other measures (or combinations of measures), cutoffs, and timepoints for early prediction of outcomes with TCZ treatment in a clinical practice setting.

\section{ACKNOWLEDGMENT}

The authors acknowledge Maribeth Bogush, $\mathrm{PhD}$, who provided writing services on behalf of F. Hoffmann-La Roche Ltd.

\section{REFERENCES}

1. Smolen JS, Aletaha D, Bijlsma JW, Breedveld FC, Boumpas D, Burmester G, et al. Treating rheumatoid arthritis to target: recommendations of an international task force. Ann Rheum Dis 2010;69:631-7.

2. Kavanaugh A, Klareskog L, Van Der Heijde D, Li J, Freundlich B, Hooper M. Improvements in clinical response between 12 and 24 weeks in patients with rheumatoid arthritis on etanercept therapy with or without methotrexate. Ann Rheum Dis 2008;67:1444-7.

3. Curtis JR, Yang S, Chen L, Park GS, Bitman B, Wang B, et al. Predicting low disease activity and remission using early treatment response to antitumour necrosis factor therapy in patients with rheumatoid arthritis: exploratory analyses from the TEMPO trial. Ann Rheum Dis 2011;71:206-12.

4. Emery P, Keystone E, Tony HP, Cantagrel A, van Vollenhoven R, Sanchez A, et al. IL-6 receptor inhibition with tocilizumab improves treatment outcomes in patients with rheumatoid arthritis

Personal non-commercial use only. The Journal of Rheumatology Copyright @ 2014. All rights reserved. 
APPENDIX 1. Statistical definitions of the relationship between improvement by Week 8 and improvement by Week 24 outcomes. FN, false negative (patients who do not achieve improvement criteria by Week 8 but achieve Week 24 disease activity threshold); FP, false positive (patients who achieve improvement criteria by Week 8 but do not achieve Week 24 disease activity threshold); NPV, negative predictive value; PPV, positive predictive value; TN, true negative (patients who do not achieve improvement criteria by Week 8 and do not achieve Week 24 disease activity threshold); TP, true positive (patients who achieve improvement criteria by Week 8 and Week 24 disease activity threshold).

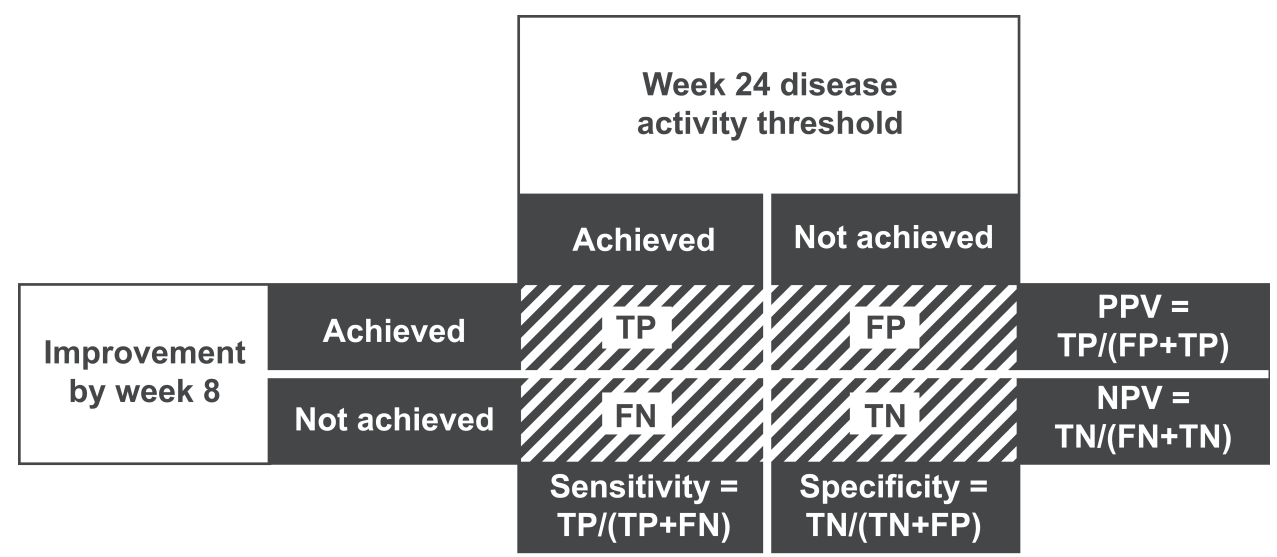

refractory to anti-tumour necrosis factor biologicals: results from a 24-week multicentre randomised placebo-controlled trial. Ann Rheum Dis 2008;67:1516-23.

5. Smolen JS, Beaulieu A, Rubbert-Roth A, Ramos-Remus C, Rovensky J, Alecock E, et al. Effect of interleukin-6 receptor inhibition with tocilizumab in patients with rheumatoid arthritis (OPTION study): a double-blind, placebo-controlled, randomised trial. Lancet 2008;371:987-97.

6. Kremer JM, Blanco R, Brzosko S, Burgos-Vargas R, Halland AM, Vernon E, et al. Tocilizumab inhibits structural joint damage in rheumatoid arthritis patients with inadequate responses to methotrexate: results from the double-blind treatment phase of a randomized placebo-controlled trial of tocilizumab safety and prevention of structural joint damage at one year. Arthritis Rheum 2011;63:609-21.

7. Genovese MC, McKay JD, Nasonov EL, Mysler EF, da Silva NA, Alecock E, et al. Interleukin-6 receptor inhibition with tocilizumab reduces disease activity in rheumatoid arthritis with inadequate response to disease-modifying antirheumatic drugs: the tocilizumab in combination with traditional disease-modifying antirheumatic drug therapy study. Arthritis Rheum 2008;58:2968-80.

8. Jones G, Sebba A, Gu J, Lowenstein MB, Calvo A, Gomez-Reino $\mathrm{JJ}$, et al. Comparison of tocilizumab monotherapy versus methotrexate monotherapy in patients with moderate to severe rheumatoid arthritis: the AMBITION study. Ann Rheum Dis 2010;69:88-96

9. Yazici Y, Curtis JR, Ince A, Baraf H, Malamet RL, Teng LL, et al. Efficacy of tocilizumab in patients with moderate to severe active rheumatoid arthritis and a previous inadequate response to disease-modifying antirheumatic drugs: the ROSE study. Ann Rheum Dis 2012;71:198-205.

10. Burmester GR, Feist E, Kellner H, Braun J, Iking-Konert C, Rubbert-Roth A. Effectiveness and safety of the interleukin 6-receptor antagonist tocilizumab after 4 and 24 weeks in patients with active rheumatoid arthritis: the first phase IIIb real-life study (TAMARA). Ann Rheum Dis 2011;70:755-9.
11. Cohen SB, Emery P, Greenwald MW, Dougados M, Furie RA Genovese MC, et al. Rituximab for rheumatoid arthritis refractory to anti-tumor necrosis factor therapy: results of a multicenter, randomized, double-blind, placebo-controlled, phase III trial evaluating primary efficacy and safety at twenty-four weeks. Arthritis Rheum 2006;54:2793-806.

12. Smolen JS, Kay J, Doyle MK, Landewe R, Matteson EL, Wollenhaupt J, et al. Golimumab in patients with active rheumatoid arthritis after treatment with tumour necrosis factor alpha inhibitors (GO-AFTER study): a multicentre, randomised, double-blind, placebo-controlled, phase III trial. Lancet 2009;374:210-21.

13. Burmester GR, Blanco R, Charles-Schoeman C, Wollenhaupt J, Zerbini C, Benda B, et al. Tofacitinib (CP-690,550) in combination with methotrexate in patients with active rheumatoid arthritis with an inadequate response to tumour necrosis factor inhibitors: a randomised phase 3 trial. Lancet 2013;381:451-60.

14. Pincus T, Furer V, Keystone E, Yazici Y, Bergman MJ, Luijtens K RAPID3 (Routine Assessment of Patient Index Data 3) severity categories and response criteria: similar results to DAS28 (Disease Activity Score) and CDAI (Clinical Disease Activity Index) in the RAPID 1 (Rheumatoid Arthritis Prevention of Structural Damage) clinical trial of certolizumab pegol. Arthritis Care Res 2011;63:1142-9.

15. Hosmer DW. Applied logistic regression. 2nd ed. New York: Wiley-Interscience; 2000.

16. Smolen JS, Landewe R, Breedveld FC, Dougados M, Emery P, Gaujoux-Viala C, et al. EULAR recommendations for the management of rheumatoid arthritis with synthetic and biological disease-modifying antirheumatic drugs. Ann Rheum Dis 2010;69:964-75.

17. Curtis JR, Ogale S, Devenport J, Lepley D. Effects of tocilizumab dose escalation on disease activity in adult rheumatoid arthritis patients with inadequate response at 16 weeks [abstract]. Arthritis Rheum 2011;63 Suppl :S867. 
APPENDIX 2. Baseline patient (DMARD-IR population) demographics and characteristics, stratified by response by Week 8.

\begin{tabular}{|c|c|c|c|c|c|c|}
\hline $\begin{aligned} \geq & 50 \% \text { Improvement in } \\
& \text { SJC66 by Week } 8\end{aligned}$ & $\begin{array}{c}\text { Yes, } \\
\mathrm{n}=386\end{array}$ & $\begin{array}{c}\text { No, } \\
\mathrm{n}=624\end{array}$ & $\begin{array}{c}\text { Yes, } \\
\mathrm{n}=328\end{array}$ & $\begin{array}{c}\text { No, } \\
\mathrm{n}=284\end{array}$ & $\begin{array}{c}\text { Yes, } \\
\mathrm{n}=754\end{array}$ & $\begin{array}{c}\text { No, } \\
\mathrm{n}=652\end{array}$ \\
\hline Age, yrs, mean (SD) & $51.6(12.5)$ & $52.4(12.8)$ & $51.9(12.8)$ & $50.9(12.5)$ & $52.8(12.5)$ & $52.8(12.0)$ \\
\hline \multicolumn{7}{|l|}{ Sex, n (\%) } \\
\hline \multicolumn{7}{|l|}{ Race, n (\%) } \\
\hline $\begin{array}{l}\text { American Indian or } \\
\text { Alaska Native }\end{array}$ & $36(9.3)$ & $33(5.3)$ & $28(8.5)$ & $13(4.6)$ & $65(8.6)$ & $51(7.8)$ \\
\hline Asian & $25(6.5)$ & $63(10.1)$ & $19(5.8)$ & $23(8.1)$ & $70(9.3)$ & $57(8.7)$ \\
\hline Black & $19(4.9)$ & $25(4.0)$ & $9(2.7)$ & $15(5.3)$ & $22(2.9)$ & $37(5.7)$ \\
\hline Other & $45(11.7)$ & $40(6.4)$ & $37(11.3)$ & $29(10.2)$ & $55(7.3)$ & $41(6.3)$ \\
\hline Baseline RF-positive, $\mathrm{n}(\%)$ & $287(74.4)$ & $489(78.4)$ & $266(81.1)$ & $223(78.5)$ & $617(81.8)$ & $508(77.9)$ \\
\hline $\begin{array}{l}\text { Previous DMARD/anti-TNF, n, } \\
\text { median (range) }\end{array}$ & $1(0-10)$ & $1(0-8)$ & $1(0-8)$ & $1(0-8)$ & $1(0-8)$ & $1(0-9)$ \\
\hline Duration of RA, yrs, mean (SD) & $8.8(8.4)$ & $9.2(8.4)$ & $8.9(7.9)$ & $8.6(7.6)$ & $9.1(8.2)$ & $9.6(8.8)$ \\
\hline $\begin{array}{l}\text { At Least Moderate RAPID3 } \\
\text { response by Week } 8\end{array}$ & $\begin{array}{c}\text { Yes, } \\
\mathrm{n}=499\end{array}$ & $\begin{array}{c}\text { No, } \\
\mathrm{n}=511\end{array}$ & $\begin{array}{c}\text { Yes, } \\
\mathrm{n}=381\end{array}$ & $\begin{array}{c}\text { No, } \\
\mathrm{n}=231\end{array}$ & $\begin{array}{c}\text { Yes, } \\
\mathrm{n}=937\end{array}$ & $\begin{array}{c}\text { No, } \\
n=469\end{array}$ \\
\hline Age, yrs, mean (SD) & $51.8(12.7)$ & $52.4(12.7)$ & $52.3(12.6)$ & $50.0(12.7)$ & $52.6(12.5)$ & $53.3(11.7)$ \\
\hline \multicolumn{7}{|l|}{ Sex, n $(\%)$} \\
\hline Female & $412(82.6)$ & $421(82.4)$ & $313(82.2)$ & $198(85.7)$ & $777(82.9)$ & $377(80.4)$ \\
\hline Male & $87(17.4)$ & $90(17.6)$ & $68(17.8)$ & $33(14.3)$ & $160(17.1)$ & $92(19.6)$ \\
\hline $\begin{array}{l}\text { Oral corticosteroids at baseline, } \\
\mathrm{n}(\%)\end{array}$ & $328(65.7)$ & $285(55.8)$ & $248(65.1)$ & $144(62.3)$ & $528(56.4)$ & $251(53.5)$ \\
\hline Baseline RF-positive, n (\%) & $380(76.2)$ & $396(77.5)$ & $315(82.7)$ & $174(75.3)$ & $771(82.3)$ & $354(75.5)$ \\
\hline $\begin{array}{l}\text { Previous nonbiologic DMARD/ } \\
\text { anti-TNF, n, median (range) }\end{array}$ & $1(0-7)$ & $1(0-10)$ & $1(0-8)$ & $1(0-6)$ & $1(0-9)$ & $1(0-8)$ \\
\hline Duration of RA, yrs, mean (SD) & $8.6(8.3)$ & $9.5(8.5)$ & $9.0(8.2)$ & $8.4(7.0)$ & $9.1(8.3)$ & $9.8(8.8)$ \\
\hline
\end{tabular}

DAS28: Disease Activity Score using 28 joints; DMARD: disease-modifying antirheumatic drug; DMARD-IR: DMARD inadequate response; RAPID3: Routine Assessment of Patient Index Data 3; RA: rheumatoid arthritis; SJC66: swollen joint count based on 66 joints; TCZ: tocilizumab; RF: rheumatoid factor; TNF: tumor necrosis factor. 
APPENDIX 3. Baseline patient (anti-TNF-IR population) demographics and characteristics.

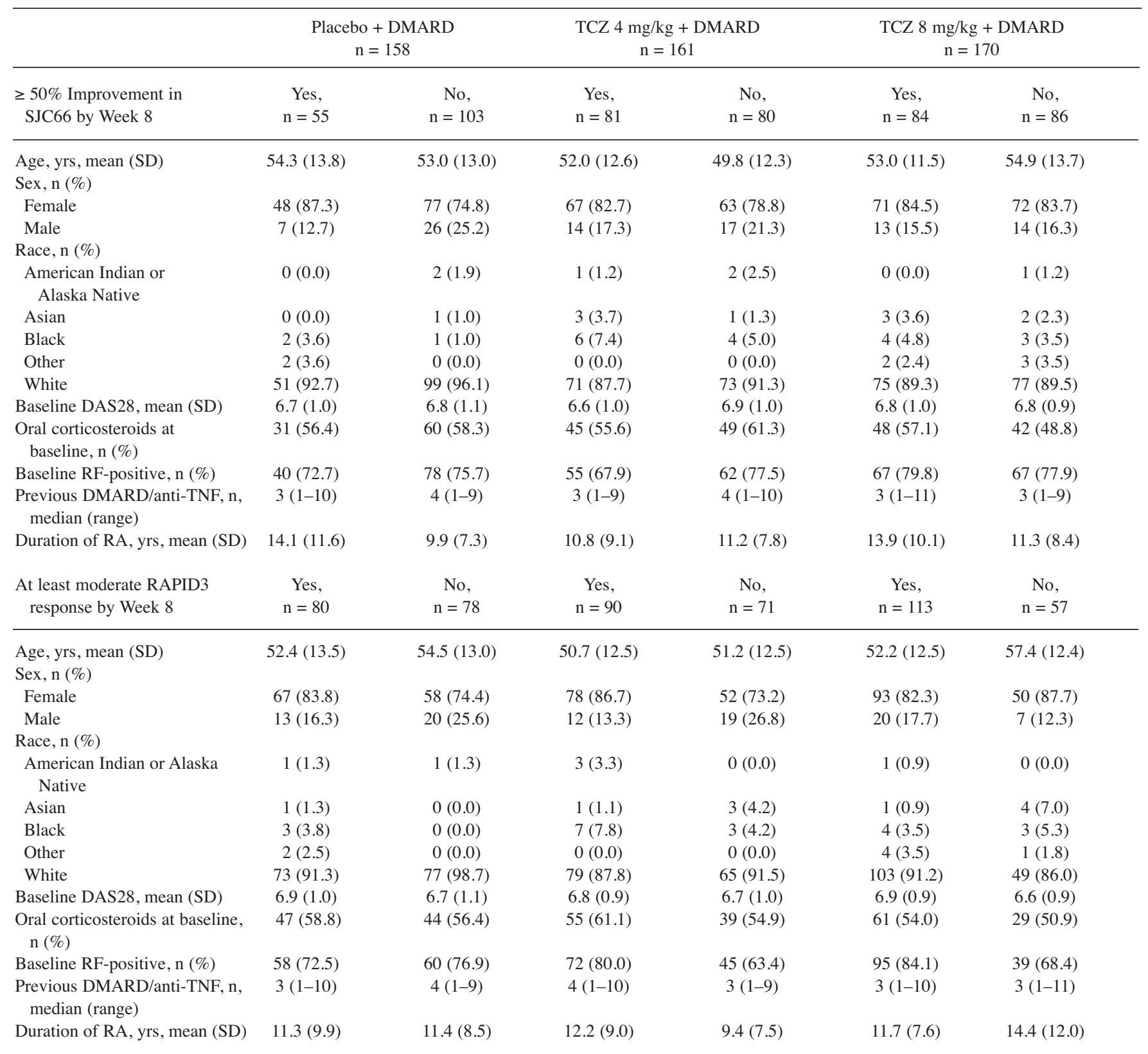

DAS28: Disease Activity Score using 28 joints; DMARD: disease-modifying antirheumatic drug; RAPID3: Routine Assessment of Patient Index Data 3; RA: rheumatoid arthritis; SJC66: swollen joint count based on 66 joints; TNF: tumor necrosis factor; anti-TNF-IR: TNF inadequate response; TCZ: tocilizumab; RF: rheumatoid factor; 